\title{
LOS GODOS Y EL IMPERIO ROMANO: LOS MECANISMOS DE INTEGRACIÓN «DEL EXTRANJERO, EL OTRO Y EL EXTRAÑO» EN EL BAJO IMPERIO
}

José Ángel Castillo Lozano Doctorando, Universidad de Murcia

Recibido: 4/12/2014

Revisado: 17/02/2015
Aceptado: $18 / 03 / 2015$

Publicado: 30/05/2015

\section{RESUMEN}

En estas líneas vamos a intentar recoger, analizar y estudiar los distintos instrumentos que el poder romano utilizó para acoger a los pueblos bárbaros en general y a los godos en particular en su propio territorio. Por ello, haremos un viaje desde el incierto origen de los godos hasta sus primeros contactos con Roma y su posterior inclusión en el organigrama estatal romano. Para ello, criticaremos determinadas fuentes literarias de este momento histórico y obras historiográficas clásicas que tienen una concepción bastante peyorativa de este fenómeno. Todo esto servirá para mostrar de forma sintetizada como Roma se valió de estos bárbaros y estos no fueron la causa última de su caída sino un recurso estatal para asegurar su supervivencia.

\section{Palabras Clave}

Godos; Metamorfosis del estado romano; Barbarización de la Administración; Barbarización del Ejército; Inclusión; Integración.

\section{ABstract}

In the following lines we will try to gather, analyze and study the different instruments the Roman power utilized to embrace the barbarian peoples generally speaking and the Goths more specifically in their own territories. This is why we will go all the way through the history, from the uncertain origin of the Goths to their first contact with Rome and their later integration into the Roman state organization. In order to do so, we will evaluate different literary sources from this historical period and certain classical historiographical literary works that have quite a derogatory perception of this phenomenon. All of it will illustrate in a synthesized way how Rome used these barbarian peoples and they were not the last reason for its decline, but a valuable state resource to assure its survival.

\section{KEYWORDS}

Goths; Roman State's metamorphosis; Barbarization of the Administration; Barbarization of the Army; Inclusion; Integration.

joseangelcastillolozano@hotmail.com

joseangel.castillo1@um.es 


\section{INTRODUCCIÓN.}

De manera tradicional siempre se ha tenido la tendencia a pensar que romanos y bárbaros cohabitaron en una misma franja espacial y temporal, pero que a su vez representaban dos mundos antagónicos que estaban destinados a enfrentarse y a no entenderse. Por un lado nos encontramos al mundo romano como estandarte de la civilización y la cultura, y por el otro lado al mundo bárbaro, donde los godos se alzarían como uno de sus principales motores, como paradigma del caos, la incultura y, en definitiva, del barbarismo. Los godos se dividían en ostrogodos y visigodos, Jordanes (Historia y gesta de los godos cap.IV, 27) explica esta separación por el camino distinto que siguieron cada grupo de godos al romperse el puente por el que cruzaban. Esta rotura del puente podría explicarse como un camino simbólico que se puede comparar con el arquetipo del paso de los israelitas por las aguas del Mar Rojo, mostrándonos de esta forma Jordanes un amplio conocimiento de las escrituras bíblicas, algo que no debe extrañarnos al ser un funcionario del Imperio cristiano de Justiniano. Se trataría dicho elemento retórico de un motivo etiológico para explicar la división entre ostrogodos y visigodos. Por otra parte, Amiano Marcelino (Historias 31, 3, 4-5) señala la existencia de dos subgrupos godos en el S. IV d. C. Estos dos grupos eran los tervingios y los greutungos que para determinados historiadores eran nombres alternativos de visigodos y ostrogodos (Heather, 1991, 8; Valverde Castro, 2000, 19).

Esta versión tan negativa de estos pueblos coetáneos al Imperio romano se ha venido superando por parte de los historiadores recientes, que tienden a señalar que no hubo tal hermetismo entre estas dos civilizaciones, sino que ambas tuvieron contactos. Buena prueba de este hecho la ofrece la existencia de grandes personajes romanos de origen bárbaro, que llegaron a los más altos puestos (magistraturas) de la administración imperial y del ejército romano. Un ejemplo es el vándalo Estilicón, que llegará a ser $m a$ gister utriusque militae praesentalis y que se relacionó con la familia imperial por medio del matrimonio. Estos hechos demuestran que tuvieron que existir unos determinados mecanismos y elementos que favorecieran la inclusión de estos extranjeros, al menos de sus élites, en el aparato bajoimperial.

Para entender lo que en estas líneas vamos a explicar, debemos tener clara una idea relacionada, más que con los godos con el propio poder romano, ya que el estado que controlaba casi la totalidad de la ecúmene había cambiado y no era ese poder que deslumbraba a todos y que no tenía parangón en el resto del mundo. Poco a poco, las instituciones y bases en las que se había asentado el Alto Imperio se habían ido deteriorando, sufriendo una metamorfosis cuyo punto álgido será la conocida crisis del S. III d. C., que marcará la verdadera bisagra donde acontecieron y se asentaron una serie de cambios y fenómenos que desembocarían en una nueva realidad histórica y en un nuevo Imperio romano, fenómeno del que parece ser que se hicieron eco los propios habitantes de la época cómo afirma Alföldy (1974, 95): "Roman society was generally convinced that it was livingin an age of serious transformations, and that the result of thesechanges meant present collapse or future uncertainty for the Empire. A general transformation of the traditional order was the basic experience of people when considering contemporary events".

Tras este periodo, el mundo será testigo del nacimiento de un nuevo ente político, un estado que ha mutado y que se ha transformado en una entidad distinta a la que vislumbramos en el Alto Imperio. Dentro de este nuevo estado las relaciones con los llamados bárbaros germanos ${ }^{1}$ serán esenciales para asegurar una cada vez más difícil supervivencia. Entre esos pueblos bárbaros con los que Roma se vio obligada a pactar para asegurar su supervivencia en el plano político, es lícito mencionar a los godos, pueblo que va a ser el eje conductor de nuestro trabajo, habida cuenta de que será el primer pueblo de estas características que fundó estados duraderos, el Reino de Tolosa y el Reino ostrogodo asentado en Italia, y que consiguió una síntesis de los elementos germanos y romanos, naciendo de esta forma una cultura intelectual autónoma (Musset, 1982, 34), con grandes pensadores como San Isidoro de Sevilla o Casiodoro, por citar algunos ejemplos memorables.

De esta forma, con el término "godo" se conoce a un pueblo "germánico" originario de Escandinavia, idea que ha suscitado numerosos debates debido a que, posiblemente, no sea un pueblo como tal

1 Este término nace en un ejercicio de alteridad de las plumas de los autores grecolatinos pues esta amalgama de pueblos y tribus no tenían una conciencia unitaria ni tenemos constancia de que verdaderamente existiera el vocablo "Germania" que limitara una entidad politicoterritorial. En conclusión, este término lo utilizaban los romanos para denominar a un conjunto muy heterogéneo de pueblos que venía a ser sinónimo de “extranjeros”, ajenos al Imperio romano (López Quiroga, 2011, 179) 
sino una conformación de diversas tribus que con el paso del tiempo sufrirán un proceso de etnogénesis conformándose así una identidad común con unas raíces distintas al ir absorbiendo comunidades de otros lugares por donde pasaban en su largo periplo hacia el Mediterráneo. Los procesos de etnogénesis son claves para entender el mundo de las migraciones. Dicho concepto, esgrimido por vez primera por Reinhard Wenskus, nos hace ver las migraciones como un movimiento dinámico, constante y abierto de génesis y desarrollo de determinadas pueblos y, sus idas y venidas en las fuentes grecolatinas (López Quiroga, 2011, 178). Dicho pueblo parece que fue desplazándose hacia el sur hasta las riberas del Mar Negro. El término "godo" es frecuentemente empleado en las fuentes literarias antiguas, tanto en griego como en latín desde el S. I a. C por autores como Estrabón (Geografía $7,1,3)$, Plinio (Historia Natural, 4, 11, 99), que los denominan con el término "gutones", en Tácito (Germania, 44,1) como "gothones" o "gotones", y en Ptolomeo (Geografía, 3, 5, 8). Las evidencias arqueológicas también nos ayudan a ir completando la historia de este término. Así, la inscripción de un anillo de oro en Pietroassa, del S. IV d. C., recoge la grafía "gutani".

El uso de "invasiones y/o migraciones" por una u otra escuela historiográfica no es inocente (López Quiroga, 2011,14), por lo que debemos ser muy cautelosos a la hora de hablar de este concepto. Antiguamente se tenía la concepción historiográfica que estos movimientos fueron invasiones. Sin embargo, la historiografía actual propugna por un cambio y prefiere utilizar el término migración o penetración para alejarse del aspecto peyorativo del término invasión, ya que es probable que hubiera un devenir constante de tribus en un limes que sería más abierto de lo que pensamos, puesto que actuaría como un medio de intercambio y de convivencia entre las distintas comunidades asentadas a ambos lados de esta frontera. De esta forma, esta frontera no tendría ese valor opaco y de separación que parece que nos ha legado la tradición que ha llegado a nosotros.

2 La inscripción rezaría: "Gutani O wi hailag", lo que traducido a nuestra lengua sería algo así como: "De los Godos el Odal, consagrado sagrado”. Es decir, nos hace referencia al carácter sacro y hereditario de dicha joya. Para saber más acerca de este anillo, se puede consultar la siguiente página web (en español): http://z7.invisionfree. com/gotfornsed/ar/t9.htm (Consulta 3-XII-2014).
En cualquier caso, sabemos que estos godos se establecieron en un topos cercano al limes romano, por ende, tuvieron un contacto directo con este pueblo en el que más tarde realizarían distintas incursiones (S. III a. C.). Jordanes, en su "Origen y gestas de los godos", confunde a dicho pueblo con los dacios ${ }^{3}$, que son también conocidos como getas. Tal vez esta "confusión" no sea tal, sino una atribución intencionada por parte del autor para glorificar el pasado de este pueblo al compararlo con unos de los mayores enemigos del Imperio en el transcurso del Alto Imperio, que a punto estuvo de convertirse en una potencia imperial a la altura de Roma (Castillo Lozano, 2014, 32-33). De este modo, la obra de Jordanes es un claro ejemplo de esa inclusión del mundo godo al funcionamiento imperial $y$, al mismo tiempo, es un intento de igualar a los godos con los romanos en cuanto a fama, gloria y buen hacer ${ }^{4}$. En otras palabras, quiere convertir a los godos en un alter estado dentro del aparato romano, si bien en un régimen de igualdad. No hay que olvidar que Jordanes era un godo que trabajaba al servicio de Justiniano, e intenta por lo tanto "romanizar" a este pueblo. Contaba en definitiva con una doble mentalidad, ya que realizaba una defensa a ultranza del gobierno bizantino de Justiniano frente a su condición de godo converso (Pérez Mulero, 2013, 79). A pesar de ello, por momentos parece que los godos fueron el pueblo más importante y decidido del orbe, aunque también se los presenta como un pueblo vencido por el bizantino. Para este escritor godo las victorias de Justiniano son una prueba evidente de la continuidad del Imperio romano y con él de la estabilidad de la religión de Jesucristo, nacido en tiempo de Augusto ${ }^{5}$. De este modo, resalta la dualidad funcional de esta obra, pues no hemos de olvidar que Jordanes se inspira en la magna y desaparecida obra de Casiodoro Senador, por lo que la Gética podría mostrarnos una actividad común en el campo literario cristiano, es decir resu-

3 "Posteriormente, cuando reinaba Buruista sobre los godos, llegó a la Gotia Deceneo, en la época en la que Sila subió al poder en Roma” (Jordanes, Origen y gestas de los godos cap. XI, 67). Buruista en verdad era un rey dacio del S.II d. C y la enigmática figura de Deceneo que siempre se vinculó a la figura del anterior monarca era su consejero pero Jordanes asimila a los dacios con los godos.

4 Jordanes, Origen y gestas de los godos, cap V, 40; cap. XIV, 79 y cap. XXIII, 116.

5 Para Jordanes el Imperio romano es ese organismo político del que habla el profeta Daniel como se muestra en su obra Romana 84-85 y 255-256. 
me una obra extensa anterior actualizándola según los intereses de los cristianos. Por eso, ha llegado a tener tanto sentido la idea de Momigliano (1955, 207-245) de que el propio Casiodoro, una vez fallecido el rey ostrogodo Teodorico y con el cambio político de Ravena tras la entrada de los hombres de Justiniano, tuvo que cambiar su obra sobre la genealogía goda arriana y actualizarla a su verdadero sentimiento cristiano, aquel que le hizo fundar la comunidad de monjes de Vivarium, en el suroeste de Italia, donde la labor cultural se presentaba como un acto más de dedicación a Dios.

Dejando de lado el interesante tema de Jordanes cuyo tratamiento desviaría la naturaleza y objeto de este estudio, las primeras referencias en las fuentes literarias acerca del establecimiento de este pueblo en las fronteras del Imperio se remontan al primer tercio del S. III d. C. En concreto se menciona la existencia de contingentes godos en el ejército de Gordiano III en el 242 d. C. Esto coincide con las dos primeras oleadas de movimientos migratorios que los arqueólogos asocian a la denominada cultura de Wielbark, aunque es imposible determinar si todos los godos que entran entonces en contacto con el gobierno de la ciudad "eterna" lo harían en el marco de este proceso y vinculados a esta cultura (López Quiroga, 2011, 98 y Schukin, Kazanski y Sharov, 2006).

Amparados en la crisis del S. III d.C., en la que participarían activamente contingentes de esta etnia, los godos fueron realizando una serie de campañas que les irían convirtiendo en una verdadera potencia más allá del limes romano ${ }^{6}$. De la misma forma, no hay que descartar que bajo el amparo de las guerras civiles que se vivieron en este convulso S. III d. C., muchos grupos bárbaros, entre los que se encontrarían grupos de godos, penetraran en los territorios romanos. Del poder de este pueblo daría buena cuenta del emperador Decio y su hijo Herenio Trusco en la batalla de Abrittus - también conocida como Forum Terebronii- en la que junto con el apoyo de tribus escitas y sármatas el rey godo Cniva logró derrotar a las tropas romanas, llegando incluso a segar las vidas del emperador romano y su hijo en las arenas de la batalla.

6 Tal y cómo especifica Jordanes en su obra, los godos realizarán campañas contra los vándalos y los marcomanos (Origen y Gestas de los godos, Cap. XXII), contra los gépidas (Origen y Gestas de los godos, Cap. XXIII) y los suevos cuados (Origen y Gestas de los godos, Cap. XXVI), entre otros pueblos. Dicho campo de estudio se inserta entre la realidad y el mito por lo que debemos ser muy cautelosos.
El primer gran pacto que firmaron los godos con el poder romano se produjo bajo el reinado del emperador Constantino ${ }^{7}$, cuando en el $332 \mathrm{~d}$. C., tras una victoria romana, se firmó un tratado de paz formal con los godos que habitaban en la frontera del Danubio: los tervingios (Valverde Castro, 2000, 18). Dicho tratado da sobrada muestra de las inestables relaciones políticas que habían en la zona, que sentaría cátedra a la hora de asentar las bases políticas que utilizaría Roma frente a los bárbaros durante todo el S. IV y V d. C. (Pavan, 1979, 160). En este tratado se estipulaba que los romanos pagarían un tributo en cereales y dinero a cambio de la fuerza militar de éstos, unos 40000 soldados (cifra que parece inflada por las fuentes literarias) y la apertura de nuevas rutas comerciales. De este modo la diplomacia imperial consigue estabilizar y pacificar sus fronteras danubianas implantando un nuevo estado de normalidad, que perdurará hasta la llegada del pueblo estepario que pasaría al imaginario colectivo como los azotes de Dios. La irrupción de los hunos en esas fechas alterará para siempre el statu quo alcanzado (Heather, 2008 a, 502), distorsionando los incipientes reinos godos construidos y añadiendo un factor más a la serie de acontecimientos, que acabará con el nacimiento de toda una serie de reinos germánicos que suplantarán a la mitad occidental del Imperio romano.

Además, aparte de este tratado, tenemos constancia que Constantino recurrió en dos ocasiones al reclutamiento de bárbaros: una en el 312 d. C. mientras guerreaba contra Majencio y otra mientras combatía contra Licinio en el 324 d. C. Además, este mismo emperador se hizo rodear de una guardia de guerreros godos (Speidel, 2005, 60) que sentaría cátedra para el resto de emperadores romanos pues se auguraban una fidelidad incuestionable a cambio de una paga. Además no hemos de olvidar que Constantino suprimió a la Guardia Pretoriana poco después de su victoria en el Puente Milvio so-

7 Estudiado con gran acierto por Heather, P. (1997), "Foedera and Foederati of the Fourth Century", Kingsdoms of the Empire. The Integration of Barbarians in Late Antiquity (Pohl, W., Ed), Leiden, 57-74. Si bien este es el primer gran pacto que firman romanos y godos, con anterioridad, se puede rastrear regimientos godos al servicio del imperio. En concreto, desde el año 297 d. C. en el que el tetrarca Galerio atacó a los persas con el apoyo de tropas auxiliares godas (Valverde Castro, 2000, 18). En la misma línea se manifiesta Wolfram $(1985,110)$ al pensar que ya hubieron acuerdos de este estilo estipulados entre ambas partes antes de esta fecha del $332 \mathrm{~d}$. C. 
bre Majencio, una Guardia Pretoriana que era un conformación muy peligrosa por ello la suprime y se apoya en estos bárbaros que se mostraban más fieles ante la persona que los contrataba generándose de esta forma, durante esta época, la adquisición de contingentes armados en clara oposición al ejército "estatal".

A partir del tratado firmado entre Constantino y los godos, estos últimos pasarían a ser uno de los mayores aliados y a la vez enemigos de los romanos. Baste recordar hechos como la batalla de Adrianópolis en el $378 \mathrm{~d}$. C. o el saqueo de Roma por parte de Alarico en el 410 d.C. Por consiguiente, a partir de ahora la historia de Roma se vinculaba de forma indisociable con el devenir de los godos, que representarán uno de los máximos ejemplos en lo que respecta a los estados bárbaros dentro del estado romano y del nuevo cambio de paradigma políticosocial de esta nueva época. Tras la caída política del Imperio romano de Occidente, desembocará en la creación de una serie de reinos germanos que serán el embrión de muchos estados modernos tal y como hoy los conocemos.

2. Política del Imperio con los godos antes y DESPUÉS DE SU ESTABLECIMIENTO EN LOS TERRITORIOS DEL Estado Romano.

2.1 El recurso retórico de la alteridad aplicado al pueblo godo.

Para abordar este ensayo debemos tener muy presente la idea que revela que para la existencia de un Romanus debe haber un barbarus. En otras palabras, si existe un Romanus, individuo que participa de una serie de rasgos culturales, sociales, políticos y económicos definidos, ello ocurre porque también existe su imagen contraria, la que se caracteriza por suscribir las actitudes inversas y que definen a la parte romana (positiva) por oposición y contraste. Tal imagen contraria es la del barbarus (Guzmán Armario, 2003, 331). Al respecto, es muy interesante lo que apunta Lyotard acerca del hecho de que no puede existir "a" sin "b" , es decir, no podemos co-

8 Hemos introducido una idea que está dentro de una rama de la historia que se conoce como alteridad (alter: otro). Muy ilustrativo y explicativo es lo que dice Lyotard: "Decir el otro es postularlo como diferente, distinto, es postular que existen dos términos: a [autores grecolatinos] y b [godos], y que a no es b; o sea, hay griegos y no griegos [y, luego, romanos y no romanos]. Pero la diferencia sólo adquiere interés a partir del momento en que a y b entran en un mismo sistema; hasta entonces, existía una no coincidencia pura y simple. De ahí nocer de una forma precisa la civilización romana si no indagamos en el punto de vista que tenía ésta de sus civilizaciones limítrofes, pues ahondando en las diferencias de ambas se genera una idea sustancial acerca de quiénes eran ellos mismos.

Para subrayar esta oposición se reforzó otro concepto que separaba tajantemente en el espacio, aunque incluso más en el pensamiento, ambas dimensiones, pues ambos mundos se separaban por el limes, la frontera que demarcaba el universo imperial frente a lo que en tiempos tardoantiguos se conoció como Barbaricum. Dicho término designa el ámbito territorial extra límites, fuera de la frontera que delimitaba el Imperio romano. No se trata, por lo tanto, de un concepto que se aplique exclusivamente a espacios habitados por poblaciones "bárbaras" y/o "germánicas". No olvidemos que "bárbaro", concepto que los romanos acogen del mundo griego, es sinónimo de extranjero. En otras palabras, bárbaro es todo aquel que es ajeno a Roma (López Quiroga, 2011, 174; Elton, 1996, 126)

Así pues, estamos comprobando que el pueblo godo "heredó" los arquetipos que el mundo romano asignaba a los "bárbaros", unos arquetipos que van cambiando tanto en cuanto que el propio cosmos romano va cambiando, por lo que necesita buscar otros portaestandartes de la barbarie. En definitiva, el mundo romano necesita si no una creación corpórea de un pueblo bárbaro enemigo, sí al menos una imaginaria, de ahí que los godos ocupen este lugar, un lugar que con anterioridad había ocupado la feritas celta, la perfidia púnica, o los propios germanos.

El pueblo godo fue un relevo más en esa amalgama de representantes de la barbarie (Guzmán Armario, 2003, 336). Así, el godo durante un tiempo resultó ser el representante perfecto para encarnar toda la pujanza destructiva fruto del barbarismo que llevaba consigo, y el propio Amiano Marcelino los destaca por encima de otros pueblos por la gravedad de sus crímenes ${ }^{9}$. Dicha idea se realizó por el desconocimiento que el mundo mediterráneo tenía de estas comunidades y por la "pérdida de barbarie" que otros pueblos, como los celtas, habían superado

es más existen divergencias y, por lo tanto, una diferencia asignable o significativa entre los dos términos no pudiendo existir a sin b" (Lyotard, 1971, 142). [Nota explicativa: la traducción es propia y los corchetes de la cita se han colocado para servir de explicación a lo planteado.] $3 ; 16,7$.
9 Historias, XXXI, 5, 5; 5, 8-9; 6, 7; 8, 6-9; 16, 1; 16, 
por el fenómeno de la aculturación y de la cristianización. Esta aculturación y cristianización también llegaría al mundo godo y sus sustitutos no serían otros que ese pueblo estepario que unificó Atila y que quedó en el imaginario colectivo como el azote de Dios. Así, las fuentes literarias nos muestran a los hunos de una forma del todo peyorativa. Muy ilustrativo es el relato con tintes etnográficos que nos hace Amiano Marcelino de ellos ${ }^{10}$, o el que nos hace Jordanes ${ }^{11}$, que es muy significativo, ya que nos habla que los hunos provenían de la unión de brujas y espíritus, dos elementos del folcklore de las estepas.

De este modo, el hueco que dejan los godos como bárbaros arquetípicos, condición que ostentaban desde el siglo III d. C., es ocupado por otras nationes, que toman el relevo como adversarios de la romanidad ${ }^{12}$ y que en la mayoría de casos no son cristianas católicas. Tal y como se incide en las fuentes literarias, a partir de ahora el verdadero bárbaro será el pagano y el hereje que amenazan el buen funcionamiento del estado. Dentro de estas gentes encontramos a las tribus hunos, aunque también encontramos a otros pueblos como los vándalos asdingos y silingos, los burgundios, etc. En definitiva, el organigrama estatal necesitaba de enemigos reales o creados para llevar a cabo su política.

\subsection{La asimilación del godo al organigrama estatal romano.}

La política que adoptaron los romanos con los godos y otros pueblos "bárbaros" ha originado ríos de tinta y seguirá originando en un futuro, pues sin lugar a dudas, como se desprende del trabajo del investigador Patrick Geary (2002), el "mundo bárbaro" constituye uno de los mayores mitos e invenciones creados por el indudable genio político y militar romano. Incluso, estos godos llegaron a ser educados en un paradigma de educación latina, aunque los estudios de Bickel (1987, 327-339) inciden en la idea de que estos pueblos se inclinaron culturalmente más a Grecia que a Roma, poniendo

10 Historias libro 31, 2, 1-12. El relato comienza de este modo: "El pueblo huno, poco nombrado en las historias de la antigüedad, habita al otro lado de la pantanosa Meotis, junto a un helado océano y sobrepasa los límites de la crueldad".

11 Orígen y Gestas de los godos, cap. XXIV, 121-122.

12 Término que nace de las plumas de los historiadores romanos tardíos para hacer un claro contraste con el mundo romano que emplea el término populos o civitas. Otro término que acompaña al de nationes es el de gentes. como ejemplo la traducción de la Biblia al godo por Ulfila. En consecuencia, estamos observando una necesidad por parte del Estado romano en contar con estos pueblos, suceso debido en parte al cambio del centro de poder del interior a la periferia, a las fronteras (Sayas Abengochea y García Moreno, 1982, 40; Guzmán Armario, 2009, 24). Prueba de este desplazamiento del poder era el origen de los propios emperadores o que Roma se convirtiera en una ciudad con un fuerte valor simbólico, mientras que su poder "real" fue desplazado a otras capitalidades ubicadas en la periferia.

Estas fronteras estaban en continuo contacto con el mundo bárbaro, tal como demuestra la tendencia de la historiografía latina tardía al empezar a ocuparse de las relaciones entre emperadores y generales bárbaros, pues los segundos solían permitir a los primeros alzarse con el poder. Al mismo tiempo, hay que hablar de una escasez de esclavos, de un decrecimiento generalizado de la población fruto de epidemias, como aquélla que trajeron de Oriente las fuerzas de Lucio Vero, el corregente de Marco Aurelio, de la alta mortalidad fruto de una esperanza infantil muy baja, y de las muertes en distintas guerras. También debemos hablar de una ruralización del poder ${ }^{13}$, unida a un auge de los localismos, que generaba una serie de poderes secundarios que se autoregulaban y que estaban un tanto alejados de la política estatal. Estos motivos explicarán el hecho de que el Estado romano empezara a acoger a pueblos extra limites dentro de sus territorios para que prestaran sus servicios como militares y trabajaran los campos, pues al fin y al cabo se trataba de resucitar uno de los pilares romanos desde sus orígenes, el asylum Romulii (Guzmán Armario, 2009, 23).

A su vez, estos pueblos necesitaban a Roma, puesto que anhelaban formar parte de un Imperio al que temían, pero al que también admiraban y del que querían formar parte. En su imaginario el Imperio era un mito que conjugaba lugares de amplias riquezas y un gobierno de providencial justicia y paz. En consecuencia, no hemos de perder de vista

13 Proceso al que la historiogafía ha venido denominando como protofeudalismo (Wickham, 1984). Aún así, hay que tener mucho cuidado al hacer uso de este concepto del protofeudalismo pues son muchos los aspectos que separan la situación del Bajo Imperio del feudalismo propiamente dicho a pesar de que la escuela marxista haya querido comparar estas dos épocas al considerarlas similares en un proceso global de luchas de clases (Anderson, 1974). 
el poder simbólico que tenía Roma, y los godos aspiraban a ser como cualquier romano que habitase dentro de la "gran burbuja" que era el Imperio (Paschoud, 1980, 124). Ansiaban vestir, vivir, expresarse, y manifestarse como un romano más, y esto lo consiguieron a través del contacto con un limes mucho menos opaco y más vivo de lo que los estudios clásicos han venido mostrando. Este proceso de aculturación e interacción culminaría con la entrada y el asentamiento oficial a través de pactos con el poder de facto de estos pueblos en los territorios romanos (López Quiroga, 2011, 15). Hay numerosas razones que nos permiten argumentar que estos tratados, pactos o foedus, se firmarían o se formalizarían una vez que los no-romanos hubieran sido derrotados militarmente, aunque también hay casos que fueron convocados por la autoridad imperial como aquél que alude a la penetración de los godos en el Danubio en el 376 d. C. con el permiso del emperador Valente. En lo que concierne a los foedus, debemos saber diferenciar entre aquellos firmados en época republicana y los firmados a partir del S. III d. C. (López Quiroga, 2011, 178). Los foedus pactados en época Alto Imperial hacen referencia al acuerdo suscrito por Roma con cualquier pueblo bárbaro, con objeto de proporcionarle asistencia y ayuda, incluyendo ayuda militar. Los foedus a partir del S. III d. C. serían los acuerdos concertados entre Roma y los bárbaros casi en régimen de igualdad en el que los bárbaros prestaban ayuda militar a Roma o vigilaban/defendían determinadas zonas de otros bárbaro o facciones romanas contrarias al poder central a cambio de una paga que solía ser grano o terrenos dentro del Imperio para asentarse y formar auténticos estados dentro de un estado mayor siendo el primero en lograr esto Alarico tras alcanzar la autoridad regia entre los godos en el 395 d. C. (Wirth, 1997, 54). Es decir, a cambio de una serie de privilegios, tenían que donar una serie de servicios al Imperio (Burns, 1994, 14; Goffart, 1980).

En cualquier caso, estos extranjeros que habían habitado más allá del limes, ahora se prestaban como una solución a determinados problemas romanos, de ahí que el espíritu pragmático de Roma los acogiera, pues sin lugar a dudas resultaban más útiles para el organigrama estatal siendo habitantes de los dominios romanos que enemigos suyos (Goffart, 1989, 131-132). En resumen, el estado bajoimperial siempre fue proclive a recibir extranjeros e integrarlos, pues le convenía realizar esto
(Demandt, 1980, 76). Por ello, el godo fue catalogado antes como un aliado y defensor de Roma que como un invasor (Gaudemet, 1984, 219).

Este proceso empezó a desarrollarse cuando Roma se dio cuenta de la utilidad que podrían desempeñar estos pueblos. En consecuencia, no los atacó cuando se fueron asentando a lo largo del S. I y II d. C en los bordes de sus fronteras del Rin y el Danubio, sino que estableció contactos más o menos directos con ellos, y generó una hábil política exterior hacia estas comunidades. Tenía varios objetivos primordiales que podemos agrupar en dos elementos principales: la restauración, mejora y conservación de las infraestructuras defensivas, y la realización de incursiones. Dichas incursiones se originaban para conducir bárbaros fuera que se habían asentado en territorio romano, para castigar los culpables de estas negligencias y para servir como elemento de disuasión contra las incursiones futuras, tanto para aquellos que las habían hecho en el pasado como para aquellas tribus que aún no lo habían hecho (Seager, 1999, 604-605).

La definición de limes, de frontera, ya nos viene dada desde antiguo: "La palabra latina limes era en su origen una expresión usada por los propietarios de tierras para indicar los límites entre dos campos, por ejemplo el sendero entre dos prados. Varios autores antiguos usan la expresión para describir las fronteras exteriores del Imperio romano" "Los investigadores actuales la emplean en un sentido más amplio, para definir y concretar el sistema imperial de defensa. El despliegue de defensas lineales en los diversos limites europeos del Imperio romano no es una excepción. Bien elaborados en madera o en piedra, este tipo de defensas en forma de amurallamientos que cubren grandes extensiones, son parte habitual de las defensas limitaneas en el Rin, el Danubio o Britania desde finales del s. I d. C. Un sistema de defensas que constaría entre otras cosas de una serie de fuertes, empalizadas, y distintos contingentes. Hasta se piensa en la actualidad que pudo haber un muro similar a los de Britannia ${ }^{15}$,

14 Veleyo Patérculo, Historia romana 2, 120, 2. Un autor que parece ser que sirvió en el ejército por lo que cuenta con una experiencia militar nada desdeñable a la hora de enfrentarnos a sus escritos.

$15 \mathrm{http} / / / \mathrm{w} w \mathrm{w}$.dailymail.co.uk/sciencetech/article2412405/Is-Romanias-Trajans-Rampart-Roman-EmpiresOTHER-Hadrians-Wall.html (consulta 14/02/2014). Este nuevo hallazgo podría ser considerada como una parte más de la reestructuración del limes danubiano emprendida por 
y toda la política exterior del Estado para defender sus fronteras. Un ejemplo bastante característico al respecto es el llamado limes "germanicus" ubicado entre el Rin y el Danubio. Esta frontera fue creada durante el reinado de Domiciano y sucesivos reinados, como los de Hadriano, Antonino Pío, etc. Fue mantenido y reformado, aunque hacia la segunda mitad del S. III d. C. se hubo de abandonar esta línea ante el empuje de las tribus germanas, de modo que la frontera del Danubio y el Rin cambió de localización. Al retroceder, las fronteras quedarían en Germania Superior y en Raetia. En torno a estas fronteras se fueron asentando un grupo de población de status no bien definido, que a la larga adquirirá la ciudadanía y se integraría en la sociedad romana, ya que ésta, por el espíritu pragmático que la caracterizaba, vio que estas poblaciones eran beneficiosas para el buen funcionamiento de Roma, aunque quizás no previnieron las consecuencias sociales y políticas a medio y largo plazo (Bravo, 2009, 35).

Con el inexorable paso del tiempo, las defensas del Rin y el Danubio se habían vuelto ineficaces para detener las incursiones bárbaras, que hacían estragos en las desprotegidas provincias situadas al otro lado. También es cierto que el estado de la cuestión actual tiende a señalar que estas incursiones responden más a movimientos migratorios que al hecho de obtener botín mediante pillaje. Esto ya es un hecho de que la política exterior debía cambiar, al menos, en lo concerniente a la defensa de sus propios territorios, pues desde los tiempos en los que Marco Aurelio, el emperador filósofo, detuvo a los cimbrios, teutones y marcomanos, ninguna amenaza fuerte se había proyectado sobre las fronteras. Sin embargo, a partir del S. III d. C. las confederaciones de los bárbaros empezaron a mostrar las carencias, las debilidades y la incapacidad del ejército romano para mantener a estos extranjeros a raya. Hallazgos arqueológicos como el Tesoro de Hagenbach, el de Lingelfeld o el de Neupotz ${ }^{16}$ así lo corroboran.

A partir de este momento la política exterior consistiría en utilizar la diplomacia, la intriga política y el espionaje por encima de las armas, aunque

este emperador a la muerte de su antecesor, Trajano (98-117 d.C.), si bien esta hipótesis no podrá ser confirmada hasta que se realicen los pertinentes estudios arqueológicos.

16 El tesoro de Neupotz fue expuesto en el MARQ hace un par de años. Para saber más de esta exposición: http:// www.marqalicante.com/barbaros/ (consulta el 14-II-2014). con el origen de las confederaciones, esta diplomacia exterior fue cada vez más difícil, ya que éstas tenían una organización política y militar más complejas que una simple tribu. No obstante, este problema se solucionó con un hábil juego de alianzas políticas y pactos.

De la misma forma, debemos añadir el pago de tributos a los estados vecinos para dejar la guerra de lado. Así, un escritor tan importante para entender de esta época como Orosio dejará testimonio de este hecho que puso en jaque a la eficacia imperial ${ }^{17}$. No pocos emperadores tuvieron que recurrir a él, como Treboniano Galo (251-253 d. C.), que pactará un tributo anual con el pueblo godo para evitar a toda costa cualquier tipo de enfrentamiento abierto con éstos para poder tener la posibilidad de cerrar frentes armados, pues el peligro sasánida en el Oriente era un continuo. Para ahorrar bienes y hombres, en muchas ocasiones la administración prefería hacer un pago que tener otro frente abierto.

Así la política exterior romana invadía la política de estas tribus (y, más tarde, confederaciones) y, como si de una mano invisible se tratara, promovía facciones y líderes favorables a sus designios para así hundir, sin esfuerzos militares, cualquier tipo de política anti-romana. Este tipo de política era posible por el papel simbólico que jugaba el Imperio romano como Imperio Universal, ya que a raíz de esto Roma ejercía un papel "paternalista" con sus estados "vasallos", que formarían una cadena de satélites claves para el control político de determinadas áreas. De la misma forma, podemos darnos cuenta de que a partir del S. IV d. C. el elemento bárbaro adquiere un fuerte papel en la vida del imperio. Este papel será tan fuerte que gran parte de los colonos romanos de la frontera serán bárbaros que se asentarán en estas zonas o en otras desiertas, favoreciendo la producción agrícola de determinadas zonas $^{18}$. Así, según el profesor Narciso Santos, en tiempos de Constantino en las provincias del Norte un hombre de cada veinte descendía de antiguos emigrantes bárbaros (Santos Yanguas, 1976, 63), lo que la historiografía moderna ha venido definiendo como semi-bárbaros o bárbaros "romanizados". Este aumento demográfico del bárbaro y, dentro de estos, los godos, ha llevado a Cameron $(1998,59)$

17 Orosio, Historias V, 1, 10: "El tributo es el precio de la libertad. Pagamos para no tener guerras, así nuestros tiempos son felices".

18 Orosio llegará a escribir que esta gente "habían cambiado las armas por el arado” (Historias VII, 41, 7) 
a plantear la idea de que será en este periodo cronológico cuando se produzca una "barbarización" del Imperio. Dicho concepto fue ya sugerido por E. Gibbon a finales del S. XVIII en su ya clásica obra Historia de la decadencia y caída del Imperio Romano. De igual forma, determinadas fuentes literarias como Zósimo también se dieron cuenta de este fenómeno y lo criticaron ácidamente - la crítica de Zósimo viene dada al atacar a un estado que considera decadente al abrazar el cristianismo como doctrina oficial ya que él era seguidor de los antiguos dioses paganos cuya repulsa por parte del Estado romano provocó, a su juicio, el castigo de estos dioses-. Sin embargo, la mayoría de los historiadores romanos tardíos no tuvieron problemas en reconocer el importante papel que jugaron los extranjeros en el buen funcionamiento del aparato estatal. En resumidas cuentas, esto es un concepto que a nosotros nos parece cuanto menos rebatible y que debe albergar distintas matizaciones, como señalaremos en las conclusiones.

Es casi imposible saber el número de pactos/ foedus que firmaron los emperadores, no el Estado (Barnish, 1986), con los bárbaros ${ }^{19}$. De la misma forma es interesante plantear si estos foedus permitirían la inclusión de la tribu entera al aparato imperial o solo de sus élites. Para ello resulta clave un estudio de la onomástica de estos tiempos, que podría resultar más que interesante para arrojar luz a esta época tan compleja de la Antigüedad Tardía. De igual modo, no sabemos con seguridad la localización de estas externae gentes, ni siquiera sobre los términos del acuerdo, aunque en cualquier caso su ubicación respondería a territorios cercanos a las fronteras (Lee, 1993, 68; Burns, 1981, 392). Además, los bárbaros serían asentados en las peores tierras (Santos Yanguas, 1976, 138), fruto de su abandono, con poco grado de urbanización o que estuvieran aisladas. A pesar de ello, esta situación se fue invirtiendo en un proceso natural del que muchos contemporáneos no se dieron ni cuenta, pues no hubo una concepción de caída del ente político romano tanto en cuanto estos pueblos se esforzaban en aparecer como romanos. Aún de esta for-

19 Estos tipos de pactos implicaba una relación personal entre emperador y líder godo lo que en una sociedad de tintes aristocráticos reforzaba la figura del líder godo de ahí que estos jefes bárbaros buscaran firmar estos tratados que además solían llevar de forma adjunta algún tipo de nombramiento dentro del ejército romano (Valverde Castro, 2000, 33). ma, este tema es tratado por las fuentes literarias de una forma especial, con ese recurso retórico de la alteridad bárbara como describimos en el apartado anterior. De esta manera los historiadores romanos ofrecen una visión de superioridad romana sobre el bárbaro y una manifiesta desconfianza hacia estas gentes (Guzmán Armario, 2009, 26-27). Cabe la posibilidad de que estos bárbaros no estuvieran tan "barbarizados", pues no hemos de perder de vista que eran comunidades asentadas cerca de una frontera que actuaba como vehículo de intercambio de distintas ideas, a pesar de la idea de hermetismo que nos sugiere la historiografía tradicional. Es posible que estos individuos reclutados estuvieran ya tiempo atrás bajo la órbita de la cultura romana y en poco se diferenciaran con un "romano de frontera" (Chauvot, 1984, 146).

De igual manera, la diplomacia romana se nutría de los hijos de esta serie de satélites pro-romanos que iban a parar a las capitales políticas como huéspedes o, mejor dicho, rehenes para que el estado en cuestión no osara desafiar el poder romano. Uno de los casos más conocidos es el de Teodorico, rehén ostrogodo aposentado en Constantinopla tras la rebelión de su padre por el incumplimiento del foedus pactado. Este conocido personaje recibiría el título de magister militum y el de patricius, y volvería a llevar la "romanidad" a la Península Itálica tras arrebatársela a Odoacro, rey de los herulos; el emperador Zenón le otorgaría el título de rex Italiam y le acogería como un "príncipe bárbaro de Occidente".

Otro caso inverso es Aecio, que estuvo de rehén de una tribu huna y finalmente, tras un intercambio de rehenes, pudo volver a su patria. La investigadora Susan Bock se plantea que estos intercambios fueran un hecho clave para el mundo bárbaro, que pudo haber influido en el cambio de mentalidad de determinadas comunidades bárbaras. Así pues, Aecio mostró claros indicios de lo que este hecho influyó en su posterior vida militar y política, por lo que debemos plantearnos si esto no influyó a los hunos o a otros pueblos con los que se intercambiaba rehenes, pues estos rehenes bárbaros, que volvían a sus campamentos tras pasar varios años en la corte imperial, traspasaron una serie de conocimientos claves en el devenir del Imperio romano y de sus propias comunidades (Bock, 1992, 190).

Resumiendo, comprobamos cómo en este caso histórico se da punto por punto lo que hemos ex- 
plicado acerca de la actitud de Roma ante estos nuevos estados, que empezaban a nacer en torno a sus territorios y, más tarde, dentro de ellos. Las campañas militares se convierten en una excepción. El ejército romano tardoantiguo, aunque poderoso, no podía hacer frente a la cantidad de problemas que acontecían. Por ello, si era posible evitar el combate, se evitaba y, cuando se realizaba siempre se buscaba un fuerte apoyo de estos pueblos que actuarían dentro del propio cuerpo expedicionario romano, como auxiliares, aliados o federados.

Esta política, que alcanza su punto álgido en estos años, será clave para poder entender la compleja época a la que nos enfrentamos, y posteriormente el Imperio Bizantino en la etapa que sus investigadores han denominado como protobizantina, que condujo a esta política hacia nuevas cotas, tal como se ha explicado en el ejemplo de Teodorico.

\subsection{Los godos como miembros de los ejércitos romanos.}

El ejército tardoimperial fue cambiando gradualmente en esta etapa de cambio. Así, las frecuentes guerras civiles, usurpaciones, problemas en la frontera, el auge del localismo en detrimento de la centralidad, y la falta de reclutas hizo que se forjara un nuevo ejército y una nueva concepción a la hora de entenderlo, ya que el ejército dejará de ser puramente romano, hecho que podemos rastrear desde época del emperador Hadriano en las tablillas de Vindolandia con el sentimiento que guardan determinados contingentes con el terreno donde están asentados (Guzmán Armario, 2009, 23). Además, ante tal situación de crisis del poder central y las continuas usurpaciones, se percibe el papel que adquiere el ejército como fuente de poder y legitimación, pues a partir de ahora muchos emperadores serán alzados a la púrpura regia por sus propias tropas, como le pasara al emperador Juliano "El Apóstata" en la Galia. Dicho suceso ya se puede rastrear con el ascenso de los Severos al poder y se consolidará a lo largo del S. III d. C., el siglo de los emperadores-soldados. Comprobamos pues cómo el ejército se convirtió en un motor de cambio y en un paradigma de ese cambio/metamorfosis que hemos venido mencionando, y por tanto no nos ha de extrañar que a su vez este ejército sirviera como mecanismo de integración de los godos y sus propias élites a las altas esferas sociales romanas.
De esta forma, el cambio del ejército ha llevado a distintos autores como Arther Ferrill ${ }^{20}$ o Yann Le Bohec ${ }^{21}$ a señalar que uno de los factores que apremió el deterioro del Imperio occidental romano y su posterior caída, fue la introducción del bárbaro en el ejército. Sin embargo, para otros autores, como Adrian Goldsworthy ${ }^{22}$, este fenómeno no fue la condición sine qua nom que provocó la catarsis de Roma, sino que fue otro hecho más en esa amalgama de cambios que se produjeron en el mundo romano, ya que éstos fueron simultáneos a los cambios sociales, políticos y económicos que originaron un nuevo mundo.

Estamos, por tanto, ante un proceso de sobra conocido en el ejército tardoimperial. Los bárbaros, y dentro de éstos los godos, jugaban un papel fundamental, siendo reclutados bien como mercenarios, auxiliares o tropas federadas, llegando a ser lideradas por sus propios caudillos al margen del cuadro de mando romano. Además, en muchas ocasiones, llegaban a ocupar los altos cargos del ejército. Por el contrario, nunca ha habido un consenso claro acerca del valor que tuvo la introducción de estos contingentes en los ejércitos regulares imperiales.

La presencia de tropas auxiliares bárbaras en el ejército romano se visualiza desde tiempos de Julio César y el emperador Claudio. Un ejemplo sería la acuñación de una serie de aurei por parte de Claudio como agradecimiento a la ayuda prestada por tropas de batavos en su ascenso al poder en el $41 \mathrm{~d}$. C. y la conquista de Britannia en el 43-44 y 44-45 d. C. (López Sánchez y Hollard, 2010, 65). También rastreamos presencia de bárbaros en el ejército romano bajo el mandato de Marco Aurelio que utilizó a estos bárbaros en sus luchas contra ellos mismos, y Hadriano creó la unidad de los numeri (soldados de origen bárbaro) en el ejército y fueron colocados bajo el mando de un praefectus numerorum, cargo que en primeras instancias correspondió a un oficial romano, pero que con el paso del tiempo fue desempeñado por los propios jefes bárbaros. Gordiano III

20 Arthur Ferrill dice textualmente en las conclusiones de su obra La Caída del ejército romano. Causas militares (Ferril, 1998, 286): "Cuando el ejército se barbarizó, perdió su superioridad táctica y Roma sucumbió a la embestida del barbarismo"

21 Yann Le Bohec $(2004,361)$ asevera que este cambio en el ejército "desembocó en ruptura".

22 Adrian Goldsworthy (2005, 201) opina que "no todo cambió, y probablemente hubo más continuidad que la sugerida en principio por la aparición de abundantes unidades y tipos de oficiales de nuevo cuño" 
Aureliano llegaron a emplear a godos en sus guerras contra los persas, pero el ejército seguía siendo esencialmente romano. Será a partir de esta época bajoimperial cuando el ejército se vaya "barbarizando" y estos extranjeros alcancen los puestos de más alta responsabilidad dentro del ejército, hecho inimaginable hacía unas pocas centurias. Incluso llegarán a ser árbitros influyentes de las disputas dinásticas y militares dentro del corazón de Roma (Fuentes, 1997 b, 366). Ejemplos tenemos varios, pero por ser tema principal de este trabajo los godos nombraremos a los "heerkönig 23 " godos Alarico y Teodorico. Esto creará un interesante proceso que vamos a intentar explicar de forma breve en estas líneas, pues es paradigma del motor de cambio que se acechaba ya en el fatum del gobierno de la ciudad eterna.

De esta forma, Roma iba apoyando a determinados líderes bárbaros y conseguía mantener el equilibrio geopolítico en la frontera, lo que Peter Heather denominó acertadamente como un "arte de la política tardo-romana": el de la "gestión de clientelas" (Heather, 2008 b). Aunque aliados de Roma, los romanos aún los veían con cierto recelo ante sus tradiciones y leyes bárbaras, no romanas, o al menos así nos lo muestran las plumas de los escritores tardorromanos, en lo que es un interesante instrumento retórico de la alteridad romana frente al otro, al bárbaro.

El peso creciente de las gentes barbarae entre los cuadros de mando y en el ejército no hará sino acelerarse a finales del S. IV e intensificarse a comienzos del S. V d. C. (López Quiroga, 2011, 70). Aparece así en tiempos de Honorio un nuevo término que cristalizaría y formaría parte del proceso que en estas líneas estamos analizando: los bucellarii. Eran tropas del Estado romano, pero no eran romanas sino godas, que para diferenciarse llevaban unas fíbulas del "tipo ballesta" como elemento de prestigio y rango militar. Según Eunapio, los godos al servicio del Imperio llevaban una fíbula de las del "tipo ballesta" (Zwiebelknopf-Fibel) como elemento de prestigio e indicativo de su alto rango militar (López Quiroga, 2011, 70). La cronología y el contexto militar de este ítem se puede desarrollar ampliamente en el campamento militar de Aquis Quaerquennis en España (López Quiroga, 2004).

23 Término acuñado por la historiografía alemana para referirse a los caudillos de los pueblos bárbaros en movimiento y en pie de guerra, ya que la misión del rey no era otra que la dirección del pueblo en armas. De esta forma, su derecho al poder desaparecía al término de la guerra.
Uno de los medios por lo que estos germanos pasaban a formar parte del ejército romano era mediante un acuerdo o foedus entre el Emperador y estos pueblos. Las condiciones de estos pactos varían entre el pago de tributos y la vigilancia del territorio de la gens y su protección frente a los ataques de otros pueblos, siendo su duración la de la vida del propio emperador con el que establecieron el acuerdo (Barnish, 1986), por lo que a la subida de otro emperador, éste debía de volver a firmar otro foedus con ellos. Esta idea puede entrar en relación con el concepto patrimonialista del estado que tenían estos pueblos germanos y del cambio de la mentalidad y estructura política romana, un cambio que se fue gestando durante la crisis del S. III d. C. y se consolidó con las medidas y reformas realizadas bajo el reinado de Diocleciano (244-313 d. C.).

De esta manera, el jefe de este pueblo recibía el título de $d u x$, comes o magister militum de manos del emperador, títulos se prolongarán a la Edad Media, y capitanearían unas tropas federadas, dentro del organigrama romano o fuera, pero asociadas a éste. Llegaron a tener más importancia que las propias legiones, como pasó en la batalla de los Campos Cataláunico (Campus Mauriacus), en la que según Musset $(1982,32)$ el ejército romano sería una mezcla de romanos, francos, burgundios, galos armoricanos y otros bárbaros que un ejército regular, añadiendo además que contaban entre sus filas como federados a las tropas del monarca visigodo Teodorico. Podemos incidir en esta idea al observar que la Notitia Dignitatum menciona cerca de 110 regimientos como auxilia palatina ${ }^{24}$, cuyos nombres se ponen en relación directa con ciertos pueblos bárbaros y godos, ya que éstas son el resultado de unidades irregulares de aliados que actuaban bajo las órdenes de sus propios jefes nativos (conocidos como socii o foederati) en formaciones regulares (De Francisco Heredero, 2011, 49). El origen de estos auxilia palatina y su carácter étnico nos es desconocido, aunque no son muy numerosos en los años previos a la tetraquía, mientras que si lo son en el momento posterior a ésta (Zuckermann, 1993; Speidel, 1996).

24 Se puede leer una introducción de dicho documento, así cómo su traducción en la siguiente página web: http:// notitiadig.260mb.com/ (consulta el 15-XI-2014). Véase además: Neira Faleiro, C. (2003), La "Notitia Dignitatum": nueva edición crítica y comentario histórico, Universidad Complutense de Madrid. [Tesis doctoral] 
Además, se ha confirmado que durante el S. IV d. C. distintas tropas romanas acantonadas en el $l i$ mes adoptaron distintos tipos de atuendo bárbaro y adoptaron una serie de costumbres bárbaras. Los ejemplos de lo anteriormente señalado son muy numerosos y nos basta con analizar los nombres de las unidades, así los sobrenombres de regimientos como los Tervingi se podría poner en relación con el pueblo godo de los tervingios, los cornuti es una referencia a los cuernos de los cascos germanos, y el barritus no deja de ser una referencia a un grito de guerra de origen germano ${ }^{25}$. Así pues, tal como señala el profesor Bravo $(2009,33)$, de las 29 nuevas unidades militares en tiempos de Honorio sólo 3 fueron legionarias.

En este sentido es posible observar cómo la barbarización del ejército afloró en virtud de dos procesos: el reclutamiento de foederati o la integración de bárbaros (godos) como soldados regulares. Incluso podríamos ir más allá y sostener que los foederati llegarán a ser soldados regulares como, por ejemplo, se observa en la figura del rey visigodo Alarico, que en el $410 \mathrm{~d}$. C. se presenta ante las puertas de Roma como un rey godo, pero también como un romano al ostentar el título de magister militum. Sin embargo, sus tropas le son fieles a él y no al estado romano. De hecho, hay autores que hablan que la génesis de una nueva conciencia goda, aniquilada tras la dispersión que siguió a la batalla de Adrianópolis (Valverde Castro, 2000, 28), viene dada cuando el estado romano le retiraba su apoyo a determinados líderes godos que recurrían a esta para mantenerse en el poder (Burns, 1994, 276-283). Esta dualidad se ha venido presentando durante toda la historia de la política romana con el mundo bárbaro, aunque ahora alcanza un nuevo formato al integrarse en la clase dirigente. Ya hemos apuntado los ejemplos de Alarico o Teodorico, pero hay muchos más, como el vándalo Estilicón o el "último gran romano" Aecio que a pesar de ser romano, convivió (¿cómo rehén?) y se crió al otro lado de la frontera romana bajo el amparo de alguna tribu de hunos.

Ante esta tesitura se forjó una síntesis en el ejército entre elementos no romanos y elementos romanos (Pérez Sánchez, 1989, 23), en un proceso que cristalizó en el conjunto de reinos bárbaros que ocuparon el solar del Imperio romano de Occidente. Reyes visigodos como Alarico u ostrogodos como

25 Vegecio, Compendio de técnica militar III, 18, 9.
Teodorico tomaron gran parte de su identidad, símbolos de poder y de su legitimidad en una serie de potestades militares que tiempo atrás ostentaban los miembros del ejército romano, y que ellos mismos habían portado cuando habían servido bajo los estandartes de Roma (Halsall, 2003, 26), pasando estos símbolos a sus sucesores.

Hay otro interesante proceso al margen del ejército "oficial": el origen de los contingentes privados a cargo de poderosos terratenientes. Dicho proceso parte de las élites locales que empezaron a contratar sus propios ejércitos personales para enfrentarse contra saqueadores, bandidos, y también contra recaudadores de impuestos algo que se pone de manifiesto en las mismas fuentes literarias del momento. Al respecto es muy interesante el siguiente fragmento: "Sin embargo, por la cruel inquinidad romana ino son arrastrados a estos, a que no quieran ser romanos?; y por esta razón, incluso los que no huyen junto a los bárbaros, son obligados a ser bárbaros" (Salviano, De Gub. Dei, V, 23). En dicho texto, vemos deserciones romanas fruto de la fuerte presión fiscal. Esta gente será acogida más allá del limes. Observamos pues como en esta época había poca diferencia entre un romano y un no romano a no ser que fueras parte de la élite de uno u otro bando (Blázquez Martínez, 1985, 157-182).

Esto provocaba que los romanos actuaran como bárbaros y éstos como romanos, creando una coyuntura altamente compleja que favoreció la creación de estos ejércitos privados, a pesar de que la legislación de la época intentara subsanar este problema. De este modo, el Codex Theodosianus nos muestra una serie de leyes sancionadoras cuyo fin último era quitar autonomía a estos poderes locales e impedir las deserciones en los ejércitos oficiales y en el pago de los tributos al estado. En vista a lo sucedido, podemos afirmar que estas no pusieron el freno para esta fenómeno que se extendió durante buena parte de la Edad Media. Del C. Th., entre otras leyes, son especialmente reveladoras al respecto las siguientes: VII. 13.16; VII. 1.15; IX.14. 2.

Este problema que hemos venido apuntando se extendería al reino visigodo (Rosa Sanz, 1987, 261; Diesner, 1978). Estos ejércitos personales serían sin lugar a dudas mercenarios, en su mayoría bárbaros que son reclutados y contratados por la especial coyuntura que estaba aconteciendo en el occidente romano. Asistimos a un proceso de descomposición del poder central, provocando de esta forma que surjan nuevas fórmulas de uso y ostentación de 
la violencia, muy heterogéneas, mediante las cuales los oligarcas tenderán a llenar el vacío de poder o, cuanto menos, a sobrevivir en él utilizando todo aquel recurso que caiga en sus manos. Por tanto, y en palabras de Rosa Sanz, asistimos a la evolución de un "ejército como el romano, dependiente de unas jerarquías militares y al servicio del Imperio, hasta culminar en el ejército visigodo, conformado en su mayor parte por tropas pertenecientes a poderes locales que podían ponerse a favor o en contra de sus monarcas, según fuesen los intereses directos de aquéllos a quienes estaban directamente obligados" (Rosa Sanz, 1986, 225). Un ejército que no será fiel al Estado sino al poder que les paga, un poder que se desplazará a la periferia, tal y como demuestra el esplendor de determinadas villas tardorromanas (Fuentes, 1997a), que se convertirán en auténticas ciudades fortificadas, ajenas a las políticas que partían del Estado. De esta forma, estos ejércitos privados también pudieron tener una función integradora, desde el mismo momento en que la parte contratante diera una serie de derechos y pagos a la parte contratada, que bien pudieran ser tierras, lugares para asentarse o cualquier otra cosa. Un pacto parecido a un foedus, pero en este caso este pacto no es entre un emperador y una comunidad bárbara, sino entre un aristócrata y un grupo de mercenarios que pueden llevar asociados a sí a una comunidad civil.

\section{ConCLusiones.}

Tal como se ha señalado en el desarrollo del artículo, debemos saber alejarnos de esas corrientes historiográficas que antaño señalaron a los pueblos germanos como causantes directos de la caída (o el asesinato) del Imperio Romano ${ }^{26}$. A lo largo de estas páginas hemos podido comprobar cómo el Imperio necesitaba a estos bárbaros en general y a los godos en particular, y éstos a su vez ansiaban y anhelaban ser romanos, es decir, que ese supuesto enfrentamiento entre lo más puramente romano y lo germano es ficticio. De esta forma, el Imperio romano generó una serie de mecanismos que articularon e integraron al bárbaro en su propio organigrama. Estos procesos son el punto álgido de una política llevada desde los inicios del mundo romano frente al mundo bárbaro, y es la culminación de una forma de entender la política desde un punto

26 "La civilisation romaine n'est pas morte de sa belle morte. Elle a été assassinée” (Piganiol, 1947: 422) de vista pragmático, cuyo origen podemos rastrear desde los míticos tiempos de Rómulo, el fundador de la ciudad eterna. No es un fenómeno nuevo en esta época, aunque si será en ésta cuando esta inclusión de los elementos foráneos alcance su punto más alto.

Esta inserción del extranjero en el Imperio no siempre ha sido valorada de forma positiva por los historiadores, y se empezó a esgrimir un concepto peyorativo que hacía referencia a la "barbarización" del Imperio. Dicho concepto nos lleva a una pregunta clave: ¿fueron los romanos "barbarizados" o los godos "romanizados"? Por lo tanto, se aprecia la manera en que Roma pergeñó un proceso de "romanización" en los godos, así como éstos últimos ejercieron un proceso de "barbarización" en la sociedad romana tardía. En consecuencia, hay que matizar mucho la idea de la "caída" de Roma por parte de una "invasión" de pueblos foráneos, ya que el aumento de bárbaros dentro del Imperio no siempre fue de forma violenta, y aunque hubo un aumento durante los S. IV y V d. C. con entradas masivas de estas nationes, no podemos justificar que el fin del Imperio se viera influido con estos fenómenos migratorios, pues si lo aceptaramos, deberíamos admitir que la "invasión" de Roma empieza con su fundación, con el hecho de que Rómulo permitiera penetrar en su ciudad a todo tipo de gente en lo que se ha conocido como Asylum Romulii, como señala acertadamente Susan Bock en su apéndice C (Bock, 1992, 396). Por tanto, nos encontramos una sociedad fuertemente jerarquizada que encubre a su vez una sociedad muy dinámica. Se han observado determinados mecanismos e instrumentos de movilidad social, donde el extranjero podía ir ocupando una serie de magistraturas plenamente romanas. Hasta en la corte imperial hubo funcionarios bárbaros como prueban distintos estudios onomásticos.

Hemos dividido nuestro trabajo en torno al mundo más puramente administrativo, para posteriormente articular un análisis del mundo militar. El resultado que se desprende de esta investigación radica en el hallazgo de una sociedad tardorromana fuertemente militarizada, de ahí que uno de los mecanismos estatales más importantes se viera involucrado en estos mecanismos de articulación social. De esta manera, nos encontramos ante una dualidad en estos godos, pues cuando formaban parte del ejército regular romano solían ostentar cargos de procedencia romana y otros de origen bárbaro, 
como demuestra el ejemplo de Alarico, puesto que éste poseía las insignias de magister militum, pero también ostentaba la jefatura militar goda (heerkönigtum). En esta línea, las élites godas se insertaban en las romanas perfectamente, junto a unos séquitos, que siempre les acompañaban, lo que a su vez responde a la pregunta que planteamos acerca de la integración o no de amplios sectores de la población goda o solo de sus élites. Esta situación si fue una de las causas que terminó por hundir al Imperio romano de Occidente, pues estas élites extranjeras aspiraban a ser romanas, pero al mismo tiempo no renunciaban a sus jefaturas, provocando así una consolidación de una serie de poderes secundarios que privaban al poder central de poder llevar a cabo una política ordenada. Se vivía en un equilibrio inestable fruto último de estos poderes secundarios, fuertemente militarizados. Esto provocó la desaparición del Imperio romano como ente político, pues el precio a pagar frente a estas gentes barbarae fue demasiado alto, a pesar de que Roma siempre permaneció durante buena parte de la Edad Media y Edad Moderna como un mito político, muy presente en las políticas de distintos reinos e imperios como un ideal a restaurar y un espejo donde reflejar sus propias políticas. A su vez, esto nos da la clave de integración de estos pueblos, pues se adaptaron tanto sus élites como el pueblo llano propiamente dicho, aunque también hay experimentos "dualistas” entre romanos-godos, como el claro ejemplo del reino de Teodorico "El Grande" en Italia.

Estas conclusiones nos llevan a otras tesis o ideas, tales como el comportamiento del limes. Durante largo tiempo se creyó que eran unidades de defensa que cerraban y protegían al suelo romano de los ataques de pueblos extra límites. La postura defendida en este artículo es que el limes actuaría casi como un organismo vivo transmisor de ideas y valores, que haría que nuestros godos y los bárbaros en general estuvieran localizados cerca de esta hipotética línea defensiva, donde convivieran y se comportaran como auténticos romanos. Este funcionamiento se integraría en un proceso por el cual el poder se desplazaría del centro del Imperio a su periferia, como demuestran también determinados experimentos políticos, como el reino de Palmira o el Imperio Gálico.

Para finalizar, se aprecia cómo el hecho de admitir a extranjeros es un acto que se vincula directamente al espíritu político romano, en la medida en que Roma jamás dudó en sacar partido a estas gentes. Así pues, a cambio de concesiones de lotes de tierras, granos u otros bienes, obtenían una serie de servicios claves para asegurar el buen funcionamiento de su política y, como objetivo último, su propia supervivencia. Por lo tanto, hemos de librarnos de ciertos tópicos y estereotipos negativos y peyorativos que circundan esta época y a estos pueblos, con el fin de saber percibir una época compleja que sirvió de antesala para la conformación de una mentalidad distinta, época histórica que será la base para entender el significado de la Edad Media, la Edad Moderna e, incluso, buena parte de la historia contemporánea.

Bibliografía

Alföldy, G.(1974), "The Crisis of the Thisrd Century as seen by contemporaries", Greek, Roman and Byzantine Studies, 15, 89-111.

Anderson, P. (1974), Passages from Antiquity to Feudalism, Londres.

Barnish, S.J.B (1986), "Taxation, land and Barbaian settlement in the Western Empire", Papers of the British School at Rome, LIV, 170-195.

Bickel, E. (1987), Historia de la literatura romana, Madrid.

Blázquez Martínez, J. M. (1985): "La sociedad del Bajo Imperio en la obra de Salviano de Marsella. Problemas económicos y sociales”, Gerión , 3, 157-182.

Bock, S. (1992), Los hunos. Tradición e historia, Antigüedad y cristianismo IX, monografías sobre la Antigüedad Tardía, Murcia.

Bravo, G. (2009): “¿Bárbaros romanizados? Nuevas fórmulas de integración del bárbaro en la sociedad bajoimperial”, Formas de integración en el mundo romano, Actas del VI Coloquio de la Asociación Interdisiciplinar de Estudios Romanos (Bravo, G. y Salinero, R. Eds.), Madrid, $31-43$

Burns, T. S. (1981), "The Germans and Roman Frontier Policy (ca. AD 350-378)", Arheoloski Vestnik, 32, 390-404.

Burns, T. S. (1994), Barbarians within the Gates of Rome. A estudy of Roman Military Policy and the Barbarians, ca.375-425 A.D. Indiana.

Cameron, A. (1998), El mundo mediterráneo en la Antigüedad Tardía, Barcelona.

Chauvot, A. (1984), "Représentations du Barbaricum chez les barbares au service de l'Empire au Iv ${ }^{0}$ siècle après J. C.”, Ktema, 9, 145-157. 
De Francisco Heredero, A. (2011), "El ejército romano del Bajo Imperio”, Ab Initio, 2.

Demandt, A. (1980), "The Osmosis of Late Roman and Germanic Aristocracies", Das Reich und die Barbaren (Chysos, E. K. y Schawarcz, A., Eds). Viena. 75-86.

Diesner, H. J. (1978), "Bandas de criminales, bandidos y usurpadores en la España visigoda” Hispania Antiqua. Revista de Historia Antigua, III, 129-142.

Elton, H.W. (1996), "Defining Romans, Barbarians and the Roman frontier", Shifting Frontiers in Late Antiquity (Mathisen, R. W. y Sivan, H. S., Eds.), Aldershot, 126-135.

Ferrill, A. (1998), La Caída del ejército romano. Causas militares, Madrid.

Fuentes Domínguez, A. (1.997a), "Las villas tardorromanas en Hispania”, Hispania romana. Desde tierra de conquista a provincia del Imperio ( Arce, J., Ensolo, S. y La Rocca, E., Eds.), Madrid-Milán, 313-320

Fuentes Domínguez, A. (1997b), "Los ejércitos y otros síntomas de la descomposición social. Fin del Imperio romano", La guerra en la antigüedad. Una aproximción al origen de los ejércitos en Hispania. Ministerio de Defensa, 357-371.

Gaudemet, J. (1984), "L'étranger au Bas-Empire", L'Etrange. Recueils de la Société Jean Bodin pour l'Histoire Comparative des Institutions, IX/ I., 209-235.

Geary, P.J. (2002), The Myth of Nations: The Medieval Origins of Europe. Princeton.

Goffart, W. A (1980), Barbarians and Romans A. D. 418-584. Te Techniques of Acommodation, Princepton.

Goffart, W. A. (1989): "The Theme of 'The Barbarian Invasions' in Late Antique and Modern Historiography” en Goffart, W. A. -ed.- (1989), Rome's Fall and After, The Hambledon Press, Bloomsbury Collections. pp. 111-132.

Goldsworthy, A. (2005), El ejército romano, Madrid.

Guzmán Armario, F. J. (2003), "El «relevo de la barbarie»: La evolución histórica de un fecundo arquetipo clásico”, Veleia, 20, 331-340.

Guzmán Armario, F. J. (2009), “Asylum Romulii: balance histórico de la integración del otro» en la civilización romana" Formas de integración en el mundo romano, Actas del VI Coloquio de la Asociación Interdisiciplinar de Estudios Ro- manos (Bravo, G. y Salinero, R. Eds.), Madrid, 17-30.

Halsall, G. (2003), Warfare and Society in the Barbarian West, 450-900, London.

Heather, P. (1991), Goths and Romans, 332-489, Oxford.

Heather, P. (1997), "Foedera and Foederati of the Fourth Century”, Kingsdoms of the Empire. The Integration of Barbarians in Late Antiquity (Pohl, W. ,ed.), Leiden, 57-74.

Heather, P. (2008 a), "Goths and Huns", The Cambridge Ancient History, XIII. The Late Empire, A.D. 337-425, Cambridge.

Heather, P. (2008 b), La caída del Imperio romano, Barcelona.

Le Bohec, Y. (2004), El ejército romano, Barcelona.

Lee, A. D. (1993), Information and Frontiers. Roman Foreign relations in Late Antiquity. Cambridge

López Quiroga, J.(2011), Gentes Barbarae. Los bárbaros, entre el mito y la realidad. Antigüedad y cristianismo XXV, Monografías sobre la Antigüedad Tardía. Murcia.

López Quiroga, J. (2004), “La presencia germánica en Hispania en el S. V. d. C. Arqueología y procesos de etnogénesis en la Península Ibérica”, Cuadernos de Prehistoria y Arqueología de la Universidad Autónoma de Madrid, 30, 213-223.

López Sánchez, F. y Hollard, D. (2010): “Les troupes germaniques des Juleo-Claudiens: un témoignage numismatique sur l'accesion de Claude", L'armée et la monnaie II, Actes de la journée d'études du 25 avril 2009 à la Monnaie de Paris (de. D. Hollard), París, 43-66.

Lyotard, J. F. (1971), Discours, Figures, París.

Momigliano, A. (1955), "Cassiodorus and Italian Culture of His Time", Procedings of the British Academy, 41, 207-245.

Musset, L. (1982), Las Invasiones. Las oleadas germánicas, I, Barcelona.

Neira Faleiro, C. (2003), La "Notitia Dignitatum”, Nueva edición crítica y comentario Histórico, Universidad Complutense de Madrid. [Tesis doctoral].

Paschoud, F. (1980), "Le mythe de Rome à la fin de l'Empire et dans les royaumes romano-barbares", Passagio dal mondo antico al medievo da Teodosio a San Gregorio Magno, Convegno internazionale. Roma, 123-138. 
Pavan, M. (1979), "La battaglia di Adrianopoli (378) e il problema gotico nell'Imperio Romano", Studi Romani, 27, 153-165

Pérez Mulero, P. (2013), La Tradición en Jordanes. Universidad de Murcia. [Tesis de licenciatura. Trabajo Inédito]

Pérez Sánchez, D. (1989): El ejército en la sociedad visigoda, Salamanca.

Pignaniol, A. (1947), L'empire chrétien (325395). París.

Santos Yanguas, N. (1976), Los pueblos germánicos en la segunda mitad del $S . I V d$. C, Oviedo.

Sanz Serrano, R. (1986), “Aproximación al estudio de los ejércitos privados en Hispania durante la antiguedad tardia”, Gerión, 4, 225-264.

Sayas Abengocheas, J. J y García Moreno, L. A. (1982), Romanismo y Germanismo. El despertar de los pueblos hispánicos, Barcelona.

Seager, R. (1999), "Roman Policy on the Rhine and the Danube in Ammianus", The Classical Quarterly, New Series, 49/2,579-605.

Schukin, M.B, Kazanski, M., y Sharov, O. (2006), Des goths aux huns, Oxford.

Speidel, M.P. (1996), "Raising New Units for the late Roman army: auxilia palatina”, Dumbarton Oaks Papers, 50, 163-170

Speidel, M.P. (2005), Ancient Germanic Warriors. Warrior styles from Trajan's column to icelandic sagas, London.

Valverde Castro, Mํ. R. (2000), Ideología, simbolismo y ejercicio del poder real en la monarquia visigoda: un proceso de cambio, Salamanca.

Wickham, C. (1984), "The other transition: from the ancient world to feudalism", Past and Present, 103, 3-36

Wirth, G. (1997), "Rome and its Germanics Partners in the Fourth Century", Kingsdoms of the

Empire. The Integration of Barbarians in Late Antiquity (W. Pohl, Ed.), Leiden, 13-55.

Wolfran, H. (1985), Storia dei Goti, Roma.

Zuckerman, C. (1993), "Les "Barbares" romains: au sujet de l'origine des auxilia tétrarchiques", L'Armée romaine et les barbares du IIIe au VIIe siècles (M. Kazanski y F. Vallet, Eds.), Paris, 17- 20. 